\title{
Growth hormone therapy in pediatric kidney transplantation-the long-term clinical benefits beyond improvement of growth after withdrawal of pre-transplant therapy
}

\author{
Ryszard Grenda ${ }^{1}$ (D)
}

Received: 6 July 2021 / Accepted: 7 July 2021 / Published online: 20 September 2021

(c) IPNA 2021

Keywords Children · Chronic kidney disease $\cdot$ Kidney transplant $\cdot$ rhGH $\cdot$ Growth hormone

\section{Introduction}

Growth retardation is one of the significant complications of chronic kidney disease (CKD) in children. The pathogenesis is multifactorial and includes genetic factors (the parental height and syndromic pattern of a specific primary kidney disease), birth-related factors (like prematurity/small for gestational age), age at onset of CKD, a nutritional deficiency and protein-energy wasting, hormonal disturbances, inadequate metabolic control, anemia, and poor efficacy of kidney replacement therapy. Once the potentially manageable clinical risk factors are addressed in children with CKD, however they still present height between the 3rd and 10th percentile and low height velocity $(<$ the 25 th percentile persisting $>3$ months in infants and $>6$ months in children) growth hormone $(\mathrm{GH})$ therapy should be considered. GH therapy is recommended in all stages of CKD beyond stage 2 , including patients on dialysis and after kidney transplantation [1]. The improvement of growth velocity is always a primary outcome measure of GH therapy; however, administration of this hormone is associated with several other clinical effects. Impact of GH therapy on kidney function was evaluated in different studies. Experimental studies revealed that the administration of GH in CKD may induce hyperfiltration, followed by the decrease of GFR (as a consequence); however, this association was not confirmed in clinical studies, including children with CKD and treated with GH [2-6]. Pediatric kidney recipients are the group of special attention

Ryszard Grenda

r.grenda@ipczd.pl

1 Department of Nephrology, Kidney Transplantation \& Hypertension, The Children's Memorial Health Institute, Warsaw, Poland in terms of selection of an optimal approach to improve the growth deficit. Meta-analysis of randomized-controlled trials (RCTs) aimed at improving growth after transplantation has evidenced that steroid minimization by itself is an effective approach in pre-pubertal children; however, several patients still require GH therapy, if the reduced exposure to steroids is not a satisfactory measure $[7,8]$. The data from these early reports have raised a concern that $\mathrm{GH}$ administered after transplantation may induce acute rejection $[9,10]$. It was suggested that the presence of specific GH and IGF-1 receptors on lymphocytes and macrophages is of clinical importance [11]; however, the impact of GH therapy on subsets of lymphocytes relevant to the risk of acute rejection was denied in a prospective study [12]. Analysis of the potential impact of GH on T-helper cell phenotypes in pediatric kidney transplant recipients showed a temporary and clinically non-relevant increase in production of interleukins $-2,-4$ and -13 , which returned to baseline values after 16 weeks of follow-up [13]. The augmentation of proliferative and cytotoxic responses to promote the anti-alloantigen reaction in mixed leucocyte culture was reported during $\mathrm{GH}$ administration, however with no clinical relevance [14]. The higher incidence of acute rejection in patients treated with GH after kidney transplantation (compared with non-treated transplant recipients) was not confirmed in several studies, a relevant meta-analysis of randomized controlled trials and by registry data $[8,15,16]$. In one of these trials, the absence of an association between GH therapy and a higher incidence of rejection was confirmed by protocol biopsies of the kidney graft; however, this study indicated caution in recruiting immunologically unstable patients with a history of previous acute rejection episodes to post-transplant therapy with GH [17]. There were no data on a decline of kidney graft function specifically related to GH therapy conducted after kidney transplantation [18]. The meta-analysisof RCTs 
showed that the change of GFR in patients receiving GH after kidney transplantation was non inferior to that of control groups, analyzed during the trials $(p=0.35)$ [8]. In one study, the sequential values of GFR increased in patients after kidney transplantation (CKD 2-3) treated with GH, up to 6 months and then returned to baseline values. This effect was observed during, not after, withdrawal of GH therapy [19].

\section{Pre-transplant GH therapy (stopped at the time of transplantation) improves growth after transplantation in pre-prepubertal children}

In a two-center prospective observational study published in this issue of Pediatric Nephrology [20], overall 146 patients receiving a kidney transplant before the age of 8 years and then followed for (mean) 5.56 years were evaluated. The study population included the subgroups of patients receiving GH $(n=52)$ and not receiving $\mathrm{GH}(n=94)$ before transplantation. Growth hormone therapy was initiated at median age of 1.93 years, the treatment was continued over a median period of 1.23 years, and then it was stopped at the time of kidney transplantation. Post-transplant growth (height, sitting, leg length) and several other clinical parameters have been monitored on a regular basis. Syndromic cases of CKD were not included in this study. Nevertheless, in comparable anthropometric data in both subgroups at the time of transplantation, a sustained and significant increase in mean standardized growth was noted in the GH-pretreated patients up to 4 years, while in children never treated with $\mathrm{GH}$ it was reported only up to 1 year post-transplant. Consequently, the frequency of short stature was lower in the $\mathrm{GH}$ pre-treated group. In a subgroup of patients not receiving GH before transplantation, there were 17 cases (18\%), who demonstrated poor growth velocity after transplantation and at mean interval of 5.71 years post-transplant they fulfilled the criteria to introduce GH treatment. There was not such a case in a GH pre-treated group.

\section{Long-term post-transplant consequences of pre-transplant GH therapy, beyond improvement of growth}

A more striking (and not expected) observation was the long, significant, and persistent favorable effect of pre-transplant GH therapy on the late kidney function after transplantation, expressed as a higher GFR. It was maintained up to 8 years after transplantation in this group and resulted in significantly better GFR values at 10 years post-transplant, compared with non-treated patients (69 vs. $46 \mathrm{ml} / \mathrm{min} / 1.73 \mathrm{~m}^{2}$; $p<0.01)$. Other related benefits included the better control of anemia and the lower values of C-reactive protein (CRP) (as a marker of chronic inflammation) over time. The novelty of these data is related to the favorable and sustained effect of pre-transplant therapy with GH (stopped at transplantation) on long-term (up to 10 years) kidney graft function, anemia, and chronic inflammation, together with the absence of any late complications of previous therapy with GH. Interestingly, the incidence of living-related transplantations was lower among GH pre-treated children, which (in the opposite situation) might theoretically influence the better long-term graft function. On the other hand, late exposure to steroids was also lower in the GH pre-treated group, which probably was a consequence of more active attitude of the treating clinicians to lower the doses of maintenance steroid in stable patients with excellent graft function. It also means that a higher exposure to steroids in patients not receiving GH before transplantation did not prevent the development of a chronic inflammation (expressed as a high CRP value). In GH pre-treated children, receiving lower doses of steroids, the CRP values were normal.

\section{Unanswered questions}

What particular mechanism is behind the long-term effect of pre-transplant GH therapy on kidney function and inflammation status, maintained over several years after withdrawal of this treatment? Is it an immune-related mechanism? Does pre-transplant therapy with GH prevent (or is able to slow) the development of chronic allograft nephropathy (CAN) or chronic antibody-mediated rejection (cAMR)?

All previous studies related to the associations between GH therapy and activity of the immune system in pediatric kidney transplant recipients were focused on its potential stimulation by GH (during ongoing treatment) and the expected higher risk of acute rejection. Based on different data, available in experimental studies or clinical observations in non-transplant settings, some speculations on the additional effects of $\mathrm{GH}$ on the immune system might be considered. However, any suggestions on potentially immunomodulating (protective?) effects of $\mathrm{GH}$, related to the drug-related modulation of selected thymic functions, protection against oxidative stress and inflammation, or reported ability to restore some failed immunological responses in the patients with acquired immunodeficiency syndrome, might be considered only in patients remaining on continuous GH therapy (or at most, shortly after withdrawal of GH) [21-27]. Again, the data from the current study suggest, that the effect of GH on kidney graft function and active inflammation was maintained for years after withdrawal of $\mathrm{GH}$ at transplantation day, not during continuous or de novo posttransplant GH therapy. There are experimental data from 


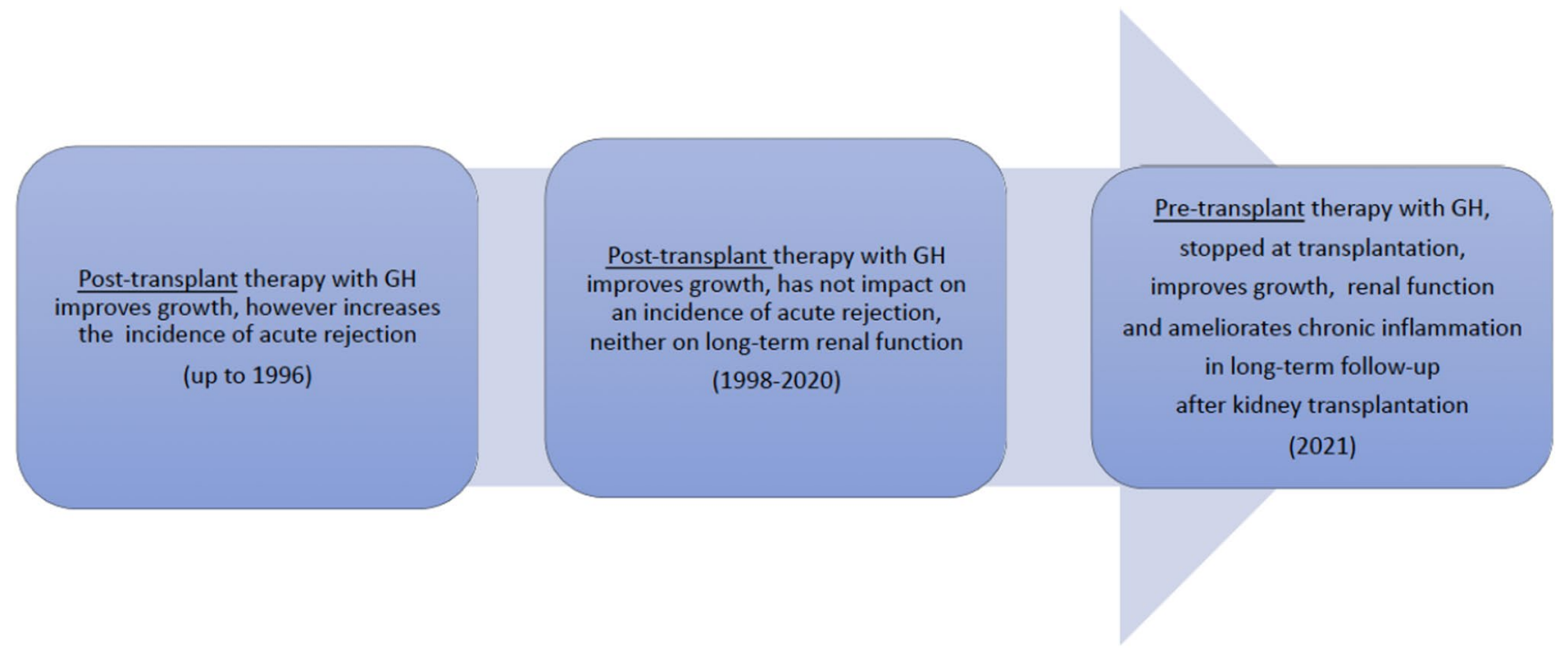

Fig. 1 Evolution of data on associations between growth hormone (GH) therapy and pediatric kidney transplantation

animal studies, aimed at reversal of fetal programming, suggesting that (relatively) short (3-week) therapy with GH, given to very young rats delivered by malnourished mothers, exerts a favorable effect on their inflammation status for a long time, until adult age. However these data are far from being directly translatable into human transplantation medicine. They just provide a message about a long-lasting effect of $\mathrm{GH}$ on the immune system after stopping the therapy in young animal subjects [28]. Apparently, longterm prospective protocol kidney biopsies, performed up to 3-4 years post-transplant in the two carefully selected groups of patients (in terms of age, comparable HLA matching, similar exposure to immunosuppression, presence of donor-specific antibodies etc.), pre-treated and non-treated with $\mathrm{GH}$ before transplantation, would be a helpful diagnostic tool to clarify this issue. However, it would be difficult to plan and conduct such a study.

What is the optimal (or minimal effective) duration of pre-transplant GH therapy, to achieve such a promising "protective" effect on long-term kidney graft function? In this study, a period of 1.23 years was reported (then $\mathrm{GH}$ was stopped at the time of transplantation).

Are these beneficial effects of GH (beyond growth improvement) age-related? Patients included in this study were young (the mean age of 1.93 years at initiation of GH therapy and 4.26 years at time of kidney transplantation) and this was one of the important factors of a further improvement of growth velocity. However, the potential association between the young age and further impact of $\mathrm{GH}$ on the other clinical benefits (beyond growth) is not clear. The immune system in young children is different from adolescents and demonstrates lower alloreactivity. Thymic output is robust during childhood. Young children have an alloimmune response characterized by low expression of several subsets of $\mathrm{T}$ and $\mathrm{B}$ cells (including those specific for immunological reactivity in organ transplantation); therefore, younger recipients have better outcomes after transplantation, suggesting the favorable role of a more naïve immune system. It is not clear whether similar secondary effects of GH (beyond growth) reported in the current study would be achieved in older patients, receiving transplantation in the second decade of life; however, (at least) a partial naïvety of immune system in the patients included in this study seems to be potentially important [29].

The evolution of data on associations between $\mathrm{GH}$ therapy and pediatric kidney transplantation is presented in Fig. 1.

\section{Conclusion}

The data from a recent two-center prospective, long-term observational study show that pre-transplant therapy with $\mathrm{GH}$, conducted in pre-pubertal children and stopped at the moment of kidney transplantation, exerts a long-term beneficial effect not only on further growth velocity, but also on kidney graft function, chronic inflammation, and the degree of anemia. Nevertheless, while the mechanism of this "protective" effect maintained for several years after termination of GH therapy is unclear, these data may encourage more extensive use of GH therapy in pretransplant children with chronic kidney disease, awaiting kidney transplantation. 


\section{Declarations}

Conflict of interest Scientific cooperation and co-authorship of the topic-related publication with one co-author of the commented manuscript.

\section{References}

1. Drube J, Wan M, Bonthuis M, Wühl E, Bacchetta J, Santos F, Grenda R, Edefonti A, Harambat J, Shroff R, Tönshoff B, Haffner D, European Society for Paediatric Nephrology Chronic Kidney Disease Mineral and Bone Disorders, Dialysis, and Transplantation Working Groups (2019) Clinical practice recommendations for growth hormone treatment in children with chronic kidney disease. Nat Rev Nephrol 15:577-589. https://doi.org/10.1038/ s41581-019-0161-4

2. Kawaguchi H, Hattori H, Ito K (1997) Somatic and renal effects of growth hormone in rats with chronic renal failure. Pediatr Nephrol 11:280284. https://doi.org/10.1007/s004670050277

3. Allen D, Fogo A, el-Hayek R, Langhough R, Friedman A (1992) Effects of prolonged growth hormone administration in rats with chronic renal insufficiency. Pediatr Res 31:406-410. https://doi.org/ 10.1203/00006450-199204000-00020

4. Tönshoff B, Tönshoff C, Mehls O, Pinkowski J, Blum WF, Heinrich U, Stöver B, Gretz N (1992) Growth hormone treatment in children with preterminal chronic renal failure: no adverse effect on glomerular filtration rate. Eur J Pediatr 151:601-607. https://doi.org/10.1007/ BF01957731

5. Maxwell H, Nair DR, Dalton RN, Rigden SP, Rees L (1995) Differential effects of recombinant human growth hormone on glomerular filtration rate and renal plasma flow in chronic renal failure. Pediatr Nephrol 9:458-463. https://doi.org/10.1007/BF00866727

6. Haffner D, Grund A, Leifheit-Nestler M (2021) Renal effects of growth hormone in health and in kidney disease. Pediatr Nephrol. https://doi.org/10.1007/s00467-021-05097-6

7. Zhang H, Zheng Y, Liu L, Fu Q, Li J, Huang Q, Liu H, Deng R, Wang C (2016) Steroid avoidance or withdrawal regimens in paediatric kidney transplantation: a meta-analysis of randomised controlled trials. PLoS ONE 11:e0146523. https://doi.org/10.1371/journ al.pone. 0146523

8. Wu Y, Cheng W, Yang XD, Xiang B (2013) Growth hormone improves growth in pediatric renal transplant recipients-a systemic review and meta-analysis of randomized controlled trials. Pediatr Nephrol 28:129-133. https://doi.org/10.1007/s00467-012-2208-7

9. Tydén G, Berg U, Reinholt F (1990) Acute renal graft rejection after treatment with human growth hormone. Lancet 336:1455-1456. https://doi.org/10.1016/0140-6736(90)93170-t

10. Broyer M (1996) Results and side-effects of treating children with growth hormone after kidney transplantation -a preliminary report. Pharmacia \& Upjohn Study Group. Acta Paediatr Suppl 417:76-79. https://doi.org/10.1111/j/1651-2227.1996.tb14304.x

11. Lebl J, Sediva A, Frisch H, Riedl S, Balzar E, Krasnicanova H (1999) Lymphocyte subsets in renal transplant recipients during growth hormone therapy. Endocr Regul 33:3-8

12. Maxwell H, Amlot P, Rees L (2000) Growth hormone and markers of immune function in children with renal transplants. Pediatr Nephrol 14:473-475. https://doi.org/10.1007/s004670050795

13. Melk A, Daniel V, Mehls O, Opelz G, Tönshoff B (2004) Longitudinal analysis of T-helper cell phenotypes in renal-transplant recipients undergoing growth hormone therapy. Transplantation 78:1792-1801. https://doi.org/10.1097/01.tp.0000147785.11967.1d

14. Benfield M, Vail A, Waldo F, Bucy R, Kohaut E (1997) The effect of rhGH in vitro on donor-specific hyporesponsiveness in pediatric transplantation. Pediatr Transplant 1:90-97

15. Maxwell H, Rees L (1998) Randomised controlled trial of recombinant human growth hormone in prepubertal and pubertal renal transplant recipients. British Association for Pediatric Nephrology. Arch Dis Child 79:481-487. https://doi.org/10.1136/adc.79.6.481

16. Fine RN, Stablein D (2005) Long-term use of recombinant human growth hormone in pediatric allograft recipients: a report of the NAPRTCS Transplant Registry. Pediatr Nephrol 20:404-408. https://doi.org/10.1007/s00467-004-1688-5

17. Fine RN, Stablein D, Cohen AH, Tejani A, Kohaut E (2002) Recombinant human growth hormone post-renal transplantation in children: a randomized controlled study of the NAPRTCS. Kidney Int 62:688-696. https://doi.org/10.1046/j.1523-1755.2002.00489.x

18. Rees L (2016) Growth hormone therapy in children with CKD after more than two decades of practice. Pediatr Nephrol 31:1421-1435. https://doi.org/10.1007/s00467-015-3179-2

19. Maxwell H, Dalton RN, Nair D, Turner C, Saunders AJ, Rigden S, Rees L (1996) Effects of recombinant human growth hormone on renal function in children with renal transplants. J Pediatr 128:177_ 183. https://doi.org/10.1016/s0022-3476(96)70386-4

20. Jagodzinski C, Mueller S, Kluck R, Froede K, Pavicic L, Gellerman J, Mueller D, Querfeld U, Haffner D, Zivicnjak M (2021) Growth hormone treatment in the pre-transplant period is associated with superior outcome after pediatric kidney transplantation. Pediatr Nephrol. https://doi.org/10.1007/s00467-021-05222-5

21. Murphy WJ, Longo DL (2000) Growth hormone as an immunomodulating therapeutic agent. Immunol Today 21:211-213. https://doi. org/10.1016/s0167-5699(00)01594-2

22. Welniak LA, Sun R, Murphy WJ (2002) The role of growth hormone in T-cell development and reconstitution. J Leuk Biol 71:381-387. https://doi.org/10.1189/jlb.71.3.381

23. Savino W, Postel-Vinay MC, Smaniotto S, Dardenne M (2002) The thymus gland: a target organ for growth hormone. Scand J Immunol 55:442-452. https://doi.org/10.1046/j.1365-3083.2002.01077.x

24. Savino W, Dardenne M (2010) Pleiotropic modulation of thymic functions by growth hormone: from physiology to therapy. Curr Opin Pharmacol 10:434-442. https://doi.org/10.1016/j.coph.2010. 04.002

25. Weigent DA (2011) High molecular weight isoforms of growth hormone in cells of the immune system. Cell Immunol 271:44-52. https://doi.org/10.1016/j.cellimm.2011.06.001

26. Lindboe JB, Langkilde A, Olsen JE, Hansen BR, BR, Petersen J, Andersen O, (2016) Low-dose growth hormone therapy reduces inflammation in HIV-infected patients: a randomized placebo-controlled study. Infect Dis (Lond) 48:829-837. https://doi.org/10.1080/ 23744235.2016.1201722

27. Herasimtschuk A, Hansen B, Langkilde A, Moyle G, Andersen O, Imami N (2013) Low-dose growth hormone for 40 weeks induces HIV-1-specific T cell responses in patients on effective combination anti-retroviral therapy. Clin Exp Immunol 173:444-453. https://doi. org/10.1111/cei.12141

28. Reynolds CM, Li M, Gray C, Vickers MH (2013) Pre-weaning growth hormone treatment ameliorates bone marrow macrophage inflammation in adult male rat offspring following maternal undernutrition. PLoS ONE 8:e68262. https://doi.org/10.1371/journal. pone. 0068262

29. Dharnidharka VR, Fiorina P, Harmon WE (2014) Kidney transplantation in children. N Engl J Med 371:549-558. https://doi.org/10. 1056/NEJMra1314376

Publisher's note Springer Nature remains neutral with regard to jurisdictional claims in published maps and institutional affiliations. 